\title{
O ensino de Artes em tempos de pandemia: reflexões sobre a experiência da Residência Pedagógica em uma escola de Ensino Médio no Sul da Bahia
}

\section{The teaching of art in times of pandemic: reflections on the experience of pedagogical residency in a high school}

\author{
Miquéias Silva Queiroz $^{1 *}$, Ivana Maria Schnitman ${ }^{1}$
}

\begin{abstract}
RESUMO
O presente artigo é fruto das ações desenvolvidas enquanto bolsista do Programa Institucional de Residência Pedagógica na Universidade Federal do Sul da Bahia (UFSB). Este artigo, parte-se da revisão histórica acerca da arte e educação no período escolanovista no Brasil na perspectiva cinematográfica nacional. Por seu turno, destaco a importância da arte-educação e da presença dos/as professores/as de artes no ensino básico, partindo de uma oficina desenvolvida com estudantes de uma escola estadual, abordando reflexões artísticas e sociais por ocasião da pandemia de coronavírus e ressaltando conceitos e fundamentos da arte-educação para a formação humana e social.
\end{abstract}

Palavras-chave: Residência Pedagógica; Ensino de artes; Educação Artística; Pandemia;

\begin{abstract}
This article is the result of actions developed while a student in the Institutional Program of Pedagogical Residency at the Universidade Federal do Sul da Bahia (UFSB). This article is part of the historical review about art and education in the New School Moviment period in Brazil in the national cinematographic perspective. In turn, I highlight the importance of art education and the presence of art teachers in basic education, starting from a workshop developed with students from a high school, addressing artistic and social reflections on the occasion of the coronavirus pandemic and highlighting concepts and fundamentals of art education for human and social formation.
\end{abstract}

Keywords: Pedagogical Residency; Teaching of arts; Artistic education; Pandemic;

1 Universidade Federal do Sul da Bahia - UFSB

*E-mail: miqueias_silva001@hotmail.com 


\section{INTRODUÇÃO}

O presente artigo aborda parte dos resultados fruto de uma investigação vinculada ao Programa Institucional de Residência Pedagógica da Coordenação de Aperfeiçoamento de Pessoal de Nível Superior (CAPES) da Universidade Federal do Sul da Bahia (UFSB), tendo como objetivo principal refletir acerca das experiências da prática docente no espaço escolar no contexto do ensino de artes durante a pandemia do Coronavírus. Parte desta investigação resultou da promoção e análise de uma oficina ministrada por graduandos da UFSB, aplicada ao um conjunto de estudantes do ensino médio, em que desenvolvemos produções, reflexões e discussões acerca da arte e do fazer artístico durante o momento de distanciamento social, destacando o papel fundamental, e a importância do arte-educador enquanto mediador de temas transversais dentro da sala de aula.

No escopo deste trabalho, iniciaremos com uma breve reflexão do contexto histórico da arte-educação no século XX no eventual cenário positivista, em que o ensino de arte e suas linguagens eram meramente ligadas a dispositivos recreativos, ou simplesmente instrumentalizados por outras áreas do conhecimento. Posteriormente, cabe nesse texto, discutir os fundamentos da arte-educação, enquanto potencializador do conhecimento autônomo e significativo no espaço escolar, considerando seus conceitos e teorias na perspectiva da arte, do artista, de educadores-artistas e educadores não-artistas. $\mathrm{Na}$ concepção que o ensino de artes não seja apenas aplicado nos mecanismos de memorização e repetição dos seus símbolos e significados conceituais, muitas vezes a gosto de professores e professoras cientificistas.

O estudo se fundamentou na análise de conteúdo, tendo como sujeitos estudantes do ensino básico que através da oficina intitulada: As dificuldades dos/as artistas locais na promoção da arte durante pandemia, permitiu contextualizar e investigar discursos dos educandos sobre o tema proposto, salientando o acompanhamento do docente em artes como importante difusor do conhecimento na escola, com ênfase a educação artística. Os depoimentos dos estudantes são diversos, e abarcam discussões e comprometimento com o tema escolhido, em que buscou-se o diálogo das artes com as políticas públicas, como também pensar caminhos e reflexões do nosso momento contemporâneo. 


\section{REVISÃO DE LITERATURA}

A perspectiva da arte e educação na tendência modernista no século $\mathrm{XX}$ e suas formas de instrumentalização: uma reflexão partindo do cinema nacional

A princípio, entre os anos de 1920 e 1930, surgia o Movimento Escola Nova, grupo composto por intelectuais, educadores e políticos. Esses, também conhecidos como pioneiros da educação brasileira ou escolanovista, traziam um modelo pedagógico com um novo ideário com objetivo de modernizar a sociedade brasileira através da educação, por meio de reformulações, mudanças de políticas públicas educacionais e curriculares (CATELLI, 2010). Por esse motivo, esses educadores viam nas artes - música, teatro, dança e cinema (CATELLI, 2010; GOMES; NOGUEIRA, 2008), uma forma de constituir uma linearidade de pensamentos acerca da implementação do cinema na educação brasileira como recurso e inclusão de filmes nas práticas escolares (CATELLI, 2010). Nessa mesma linha Gomes e Nogueira (2008) também comentam as seguintes concepções:

\footnotetext{
Entre os anos 20 e 70, as escolas brasileiras viveram experiências diversas no ensino da Arte, mas nos anos 30 e 40 dominou o Canto Orfeônico, projeto elaborado pelo compositor Heitor Villa-Lobos, que pretendia difundir a linguagem musical de maneira sistemática, juntamente com princípios de civismo e coletividade, condizentes com o pensamento político da época (BRASIL, 1997 apud GOMES; NOGUEIRA, 2008, p. 2)
}

Ademais, estes recursos eram de interesse das arenas políticas e educacionais entre liberais e antiliberais ao propor um ensino no Brasil, em que constituía o controle das massas através dos meios de comunicação e educação. Os educadores articularam políticas cinematográficas, reservando o cinema em uma perspectiva de propaganda, mobilização das massas e integração social e nacional.

Em 1937, era constituído a criação do Instituto Nacional de Cinema Educativo (INCE), que sob direção do educador Edgar Roquette-Pinto e coordenação do cineasta Humberto Mauro, conseguiram produzir centenas de filmes e documentários que eram destinados integralmente para a educação relatando experiências científicas nas áreas das Ciências Humanas, Biologia e Medicina (CATELLI, 2010). Era de se observar a grande potencialidade do cinema e suas tecnologias enquanto um grande propagador de conhecimento, em que se auxiliava aos meios de comunicação, e assim, "serviriam para formar o povo brasileiro, o trabalhador nacional, o homem do campo, enfim, para contribuir no processo de organização nacional" (CATELLI, 2010, p. 608-609). Desse 
modo, a união entre educadores e cineastas, firmavam diferentes interesses em que ambos pudessem ganhar em suas respectivas arenas de influência. O Cinema passa a ser cenário de domesticação e instrumentalização das outras áreas do conhecimento, nas crenças positivistas de Albert Kahn: a ciência como poder transformador das ações políticas e sociais (CATELLI, 2010), de modo, cujo nome tornou-se referência para os educadores, em experiências das realizações cinematográficas fomentadas pelo então empresário, com seus trabalhos relacionados ao cinema no ensino de Geografia, proporcionando, uma verdadeira viagem sobre a terra, do conhecimento das culturas, das sociedades e dos fenômenos sociais (CATELLI, 2010).

Nesse esboço, as tecnologias cinematográficas contribuíram aos educadores, um avanço nas Ciências da Saúde e da Natureza. A utilização do cinema nas áreas afins, proporcionou um acervo diversificado na medicina, como também constituiu novos avanços tecnológicos acerca do uso da imagem: "Se 1895 era um marco 'oficial' do nascimento do cinema para os historiadores do próprio cinema, para os da medicina e de suas técnicas de visualização, a data também comemorava a descoberta dos Raios X" (VIEIRA, 2003, p. 317 apud CATELLI, 2010, p. 615).

Posteriormente, essas técnicas seriam apropriadas e aperfeiçoadas pela medicina e pelas suas especialidades, como novos métodos de observação de microorganismos, na qual denominaram de microcinematografia. O cinema científico de Jean Painlevé, reformulado pelos educadores, tinha a concepção do cinema científico como estudos relacionados à indústria, a balística, a química, física e biologia, com recursos e técnicas cinematográficas como apoio à área da pesquisa. Desse modo, o cinema educativo proposto pelos cientistas e educadores, tinha o propósito de modernizar a sociedade brasileira, nos sentidos éticos e morais da elite letrada, colocando-se como vanguarda do projeto em prol da educação (CATELLI, 2010). O cinema educativo além de propor a reflexão acerca do uso do cinema na educação, trouxe consigo a domesticação do cinema brasileiro, e a instrumentalização do ensino de artes por ideologias positivistas da época, em que se pode observar até os dias atuais (GOMES; NOGUEIRA, 2008). Para Sena et al., (2019), o período da Escola Nova é marcado pelos procedimentos e métodos tradicionais aplicados à educação, em que o aluno aprende parte dos conteúdos através da memorização, uma vez que, os adeptos da Escola Nova enfatizavam que as disciplinas serviam para obter resultados específicos. Tais tendências eram consideradas inovadoras no contexto metodológico na sala aula, assim como expressa Bittencourt (2004): 
No decorrer dos anos 70, as inovações nas técnicas educacionais foram tidas como sinônimo de métodos de ensino inovadores. Assistiu-se ao crescimento do uso de audiovisuais para as áreas de ciências humanas e de kits de laboratórios para as áreas de Matemática e de ciências, particularmente. Os estudos dirigidos, palavras cruzadas e outros jogos de caça-palavras correspondiam a técnicas mnemônicas entendidas como "métodos de ensino inovadores". (BITTENCOURT, 2004, p. 225226 apud SENA et al., 2019, p. 198)

As considerações de Sena et al., (2019) sobre o uso do cinema no contexto escolar, traz a perspectiva de Marcos Napolitano em que "o cinema não tem que substituir o livro didático, mas dialogar com o conteúdo ministrado, de forma que os alunos consigam compreender o sentido do filme e busque estabelecer relações entre os conteúdos" (SENA et al., 2019, p. 199) que são trabalhados na sala de aula. A utilização do cinema e seus recursos midiáticos no ambiente escolar, deve-se primordialmente aos estudantes explicar e contextualizar, independente da área de conhecimento, explanar que o "cinema é mais que arte, é indústria, é business" (SENA et al., 2019, p. 199). Importante aqui ressaltar, que o ensino de arte durante esse tempo é rotulada como uma matéria sem as devidas importância para os processos pedagógicos para os educandos, em que a "contratação de profissionais não ou pouco qualificados, e num certo menosprezo da Arte em relação às outras disciplinas mais tradicionais" (GOMES; NOGUEIRA, 2008 p. 5) sendo assim, considerada como apenas uma atividade extraclasse e extracurricular no ensino escolar.

\section{Fundamentos da arte-educação: 0 ensino da prática libertadora}

Ao retornar para Brasil na década de 80, Paulo Freire (1989) dará início a organização de um livro de materiais didáticos, com ênfase na alfabetização e pósalfabetização de adultos nas ilhas de São Tomé e Príncipe, na qual constituiu os denominados Cadernos de Cultura Popular. Na perspectiva de que - "aprender a ler, a escrever, alfabetizar-se é, antes de mais nada, aprender a ler o mundo, compreender o seu contexto, não numa manipulação mecânica de palavras mas numa relação dinâmica que vincula linguagem e realidade" (FREIRE, 1989, p. 7). Assim, Freire ao introduzir este capítulo: A importância do ato de ler (1989), esboça as mais belas sensações e memórias do seu tempo de infância na designação da importância do ato de ler. É na infância que ocorre a primeira leitura do mundo, cuja concepção se baseia na observação dos signos, das coisas, e dos objetos que estão à nossa volta, como também das pessoas e familiares que nos rodeiam. Que de modo, permitiu-se repetir, recriar, reviver suas experiências antes de aprender as palavras escritas (FREIRE, 1989), assim, “a decifração da palavra 
fluía naturalmente da 'leitura' do mundo particular” (FREIRE, 1989, p. 9), para tanto, a palavra jamais significou a ruptura da leitura do mundo, e sim na construção da leitura da palavramundo como expresso por Paulo Freire.

A menção crítica da importância do ato de ler, se dá a partir da sua prática, uma vez que, Freire no seu tempo de escolarização, era indagado a refletir suas leituras em uma percepção crítica dos textos abordados pelos/as professores/as. Não era nesses momentos de aulas cadenciadas e mecânicas, que se podia ler o mundo - eram nos "momentos em que os textos se ofereciam à nossa inquieta procura" (FREIRE, 1989, p. 11), que proporcionasse a curiosidade de maneira dinâmica, em que estimula a vida aos textos e as palavras, ao sentido e sentimentos dos educandos. Outro ponto importante, que "reside na compreensão errônea que às vezes temos do ato de ler" (FREIRE, 1989, p. 12), é a compressão de sentidos mecanizados, em que os alunos memorizam pontos fixos, semelhante a um adestramento, resultando na irreal leitura da palavramundo.

A alfabetização de adultos, assim como assinala Freire, é antes de tudo um ato político, como também de conhecimento, autoconhecimento e criação. No processo de ensino, não se trata apenas de educar alfabetizandos como se fossem um recipientes vazios, desconsiderando suas experiências, vivências e história de vida. Ao comentar este ponto, Freire expressa: "o fato de ele necessitar da ajuda do educador, como ocorre em qualquer relação pedagógica, não significa dever a ajuda do educador anular a sua criatividade e a sua responsabilidade na construção de sua linguagem escrita e na leitura desta linguagem" (FREIRE, 1989, p. 13). Desse modo, compreende-se que a leitura da palavra não é apenas no que descreve na leitura do mundo, mas (re)escrever e (re)ler, no que diz na transformação na nossa prática consciente, que consequentemente, a leitura resulta na concepção crítica da prática transformadora do mundo (FREIRE, 1989). Para tanto, cabe refletir: como a importância do ato de ler mencionado por Freire poderia ser aplicada ao ensino de artes? Talvez a resposta possa estar simplesmente no ato de sentir, no ato de expressar, no ato de observar, como também, de contextualizar, ouvir, falar, cantar, brincar, fazer arte.

Na perspectiva de Duarte-Júnior (1981), o educador traz alguns pontos em referência da arte na educação, o artista e seu ato de criação. Em que afirma neste contexto, que "a existência da imagem mental foi, por muito tempo, considerada um escândalo ontológico, e a imaginação, praticamente, nunca deixou de ser alvo das perseguições das antropologias departamentais” (DUARTE-JÚNIOR, 1981, p. 92). Isso 
porque, através da imaginação cria-se o novo, o inimaginável, o que pode ser considerado possível ou impossível. De modo que, pensar, imaginar, refletir, criar muitas vezes é capaz de ser um ato simbólico e de resistência. Neste contexto, para que o/a artista expresse o novo, ele/ela muitas vezes precisará negar o que já existe, captar uma carga de sentimentos ao seu redor para no fim propor o novo em forma simbólica: uma obra artística. A obra de arte por si mesma, habita sentimentos e seus atos de rebeldia, que por sua vez, para se criar o novo, é preciso que o artista negue o real e busque outros caminhos para estabelecer o feito inédito (DUARTE-JÚNIOR, 2002). Neste seguimento, Rubem Alves argumenta que "somente o que diz o seu 'não' às coisas como são, mostra o desejo de sofrer pela criação do novo. O mundo da cultura seria literalmente impensável se não fosse pelos atos de rebeldia de todos aqueles que fizeram algo para construí-la” (ALVES, 1975, p. 149-150 apud DUARTE-JÚNIOR, 2002, 54-55). Isso quer dizer que, os artistas não estabelecem somente uma intuição no que se refere ao ato criacionista, mas também o desejo de transformá-las e ressignificá-las à sua visão do mundo.

Na percepção do artista, é um momento bastante pessoal, que de certa forma como um ato, que saí de dentro pra fora e aborda seu espectador de diversas maneiras - "criar ocorre uma movimentação de nossos sentimentos, que vão sendo confrontados, aproximados, fundidos, para posteriormente serem simbolizados, transformados em que formas que se ofereçam à razão, ao pensamento" (DUARTE-JÚNIOR, 2002, p. 53), sendo este é o momento fascinante em que podemos deslumbrar-se diante do nascer de uma obra partindo da visão criacionista do artista. $\mathrm{O}$ artista estimula o sentir, e cria percepções das emoções humanas na sua vida cotidiana. É como se ele possuísse "antenas que captam aqueles sentimentos em que todos estão imersos, sem conseguirem, no entanto, torná-los evidentes" (DUARTE-JÚNIOR, 2002, p. 56), sendo assim, o artista possui esta capacidade de materializar e transmitir para espectador os sentimentos concretos e subjetivos em que a todo tempo estava supostamente invisíveis nos ambientes da sociedade.

[...] o que ocorre na experiência estética, contudo, é que a consciência procura apreender o objeto desvencilhando-se dos laços condicionantes da linguagem conceitual. Nela o homem apreende o mundo de maneira total, sem a mediação parcialmente dos conceitos linguísticos. Na experiência estética suspendemos nossa "percepção analítica", "racional", para sentir mais plenamente o objeto. (DUARTE-JÚNIOR, 2002 , p. 58, grifo do autor) 
Podemos observar que muitas pessoas que se emocionam e choram assistindo filmes no cinema, enquanto outros podem não ter essa mesma reação, ou nenhuma reação, uma vez que cada um consegue compreender o que está sentindo naquele determinado momento. Assim, "somos tentados a crer que o belo se encontre nos objetos" isto é, "que a beleza é uma qualidade que eles possuem (ou não) [...] o que para mim é belo, para outro pode não ter beleza alguma" (DUARTE-JÚNIOR, 2002, p. 57). Desse modo, estamos a enxergar o mundo cada vez mais racional através da linguagem, que por ventura não exprime sentimentos e formas estéticas do ser humano. A função da obra de arte não é simplesmente a transmissão de significados ou da comunicação de palavras e reflexões complexas da mesma. A obra possui o intuito da expressão do sentimento e o sentir do artista, em que deve-se ser sentida e vivenciada (DUARTE-JÚNIOR, 2002, p. 60) ao olhos dos seus apreciadores. Nessa perspectiva Duarte-Júnior (2002) comenta:

Diante da obra de arte o espectador deixa os seus sentimentos vibrarem, em consonância com as harmonias e ritmos nelas expostos. O espectador encontra, nas formas artísticas, elementos que concretizam [...] sendo a arte uma forma de expressão, ela depende da interpretação, do sentido que o espectador lhe atribui. Como sua função não é transmitir um significados conceitual determinando, seu sentido brota dos sentimentos se seu público; ele nasce da maneira como as pessoas a vivenciam. (DUARTE-JÚNIOR, 2002, p. 61, grifo do autor)

Em outras palavras, quando o artista expõe ou apresenta uma obra artística para o seu respectivo público, o seu trabalho estará aberto para qualquer interpretação em que se inspire seus espectadores, isso porque, o artista cativa os sentimentos das pessoas e os fazem enxergar de outras maneiras. Uma vez exposto, é um caminho sem volta - o sentido da obra do artista estará propício aos ideários daqueles que apreciam.

Segundo Duarte-Júnior (1981) a imaginação é um campo de estudos, em que trás os sentimentos e cria experiências estéticas - como se fosse um certo prazer de apreciar momentos e eventos em que conduz uma carga expressiva e imagética nas nossas vidas. Nessa perspectiva, Duarte-Júnior possui a ideia que nós estamos passando por um processo de transformações mentais decorrente do capitalismo e os meios de consumo, em que seguimos o mundo de formas mais racional e que por outro lado acabamos esquecendo dos nossos sentimentos, por esse motivo, o autor afirmar que "numa civilização onde cada vez são mais estreitos os espaços destinados à imaginação, onde a racionalismo elegeu o 'realismo' como norma de ação, e onde até mesmo o prazer deve ser comprado, a arte pode constituir-se num elemento libertador" (DUARTE-JÚNIOR, 1981, p. 96). Para as crianças, a arte está ligada mais pelo ato do fazer sem fins estéticos 
e significativos. Na arte-educação, por sua vez, a matéria de arte se esboça como uma atividade extraclasse voltada para os jogos lúdicos (DUARTE-JÚNIOR, 1981, p. 102). Nessa concepção, será algo mais experimental, um passatempo em que as aulas de artes naquele momento poderão ser taxadas como uma disciplina não muito séria ou menos importante para o currículo escolar daquelas crianças (DUARTE-JÚNIOR, 1981; 2002).

\title{
A Residência Pedagógica e o fazer educacional através de oficinas
}

Promovida pelo Ministério da Educação (MEC), e pela CAPES, a Residência Pedagógica, devorante RP, tem como objetivo principal promover o aperfeiçoamento dos licenciandos de graduação de nível superior à prática docente nas escolas de ensino básico, de maneira que introduz os residentes no ambiente de ensino- aprendizagem em que os possibilite observar o contexto escolar, e investigar na prática docente de forma autônoma e orientada, com também possam "experienciar a práxis educacional do educador e assim enxergar o real cotidiano escolar, pois inserido nessa realidade realizamos o diagnóstico sobre o ensino, a aprendizagem, a didática e a metodologia" (SANTOS et al., 2019, p. 2). A Residência Pedagógica estimulada pela UFSB, traz nos seus documentos norteadores, o conceito de interdisciplinaridade entre as suas Licenciaturas interdisciplinares (LIs), como também entre os seus Bacharelados interdisciplinares (BIs), coligando-as com as diversas áreas do conhecimento - Ciências humanas, linguagens, artes, exatas, saúde e educação. De acordo com Fazenda (2008), ao comentar sobre este conceito expressa o seguinte:

\begin{abstract}
Interdisciplinaridade é definida como interação existente entre duas ou mais disciplinas, verificamos que tal definição pode nos encaminhar da simples comunicação das idéias até a integração mútua dos conceitos chaves da epistemologia, da terminologia, do procedimento, dos dados e da organização da pesquisa e do ensino relacionando-os (FAZENDA, 2008, p. 94).
\end{abstract}

Na mesma linha, Fazenda e Souza (2012), baseando-se na ideia de Cardoso (1995), fomentam a discussão da interdisciplinaridade aplicada à saúde e educação, em que ressalta que o papel dos/as professores/as e alunos/as devem ser compreendido de forma mútua, em que a educação enquanto processo deva prevalecer a autonomia dos indivíduos em promover formação como também autoformação dos mesmos. Em suas palavras:

Nem o educador e nem o educando são, isoladamente, o centro energético que impulsiona o processo de aprendizagem. Este centro está no encontro entre eles, como numa dança em que os passos marcados 
acabam por fluírem livremente, tornando quase imperceptível quem conduz e quem é conduzido. Não se trata de tirar o papel imprescindível do mestre, adotando uma postura não-diretiva. Para que isso se torne possível, a relação educador-educando não pode se dar apenas no plano intelectual, mas também no plano da sensibilidade, sentimentos e emoções. O equilíbrio entre o intelectual e o afetivo é fundamental na prática de um ensino (CARDOSO, 1995, p. 51 Apud FAZENDA; SOUZA, 2012, p. 112-113).

Nessa perspectiva, a RP atua neste seguimento de partilha de conhecimentos acadêmicos em diálogo com seus estudantes e a comunidade externa no qual a instituição está inserida, constituindo assim, um eixo universidade-sociedade em que promove o comprometimento com a educação básica no sul do estado da Bahia. Partindo dessa concepção teórica-metodológica na qual somos proporcionados durante todo o percurso da Residência Pedagógica, somos indagados muitas vezes a refletir - O que é a educação? O que é um saber? Somente os/as professores/as e academias que são dotadas do conhecimento cujo são forjadas por especialistas?

De acordo com os estudos do Núcleo TRAMAS - grupo composto por pesquisadores/as e educadores/as - aborda uma série de questões acerca da saúde, conflitos ambientais, territorialidade e metodologias pedagógicas em contexto das comunidades rurais, ribeirinhas e pequenos agricultores no estado do Ceará, na qual, relaciona a educação e os saberes do campo, no pensamento crítico freireano ao ambiente acadêmico, em que assinala o "epistemicídio" (SANTOS; MENESES, 2010 apud LEÃO; MELO; GOMES, 2016) dos saberes tradicionais, desperdiçando e descartando suas experiências de vida cotidianas tão debruçadas por Freire. Os autores mencionam o tripé científico tradicional da academia, no que se refere ao ensino-pesquisa-extensão: “o ensino à transmissão de conhecimento, a pesquisa à ideia de produção do saber realizada apenas por especialistas, a extensão ao propósito de intervenção em processos sociais" (LEÃO; MELO; GOMES, 2016, p. 3). Neste contexto, em busca de superar as barreiras impostas ao longo do tempo do modelo tradicional da acadêmica, o Núcleo TRAMAS realçou a valorização dos saberes populares, tradicionais das comunidades e seus conhecimentos do território que ali atuavam. Seguidamente, destacaram dimensões em que puderam aprender e ensinar entre crianças, jovens, adultos, professores e professoras do ensino básico, "a construção compartilhada de conhecimentos, de forma interdisciplinar, considerando a diversidade de sujeitos e saberes e as demandas sociais" (LEÃO; MELO; GOMES, 2016, p. 4), e para que assim promovesse uma Pedagogia do Território. 
Nesse sentido, tanto lá e aqui, a promoção da valorização dos saberes tradicionais e das comunidades - indígenas, quilombolas, rurais, periferias entre outras - não ocorre de forma diferente. A Residência Pedagógica - UFSB, ao incentivar seus residentes na construção de materiais didáticos e oficinas de saberes-interdisciplinares em que parte-se das bases epistemológicas da educação, nos proporciona uma experiência da cosmovisão dessas populações e culturas na nossa sociedade, como também nos aproxima da realidade dessas pessoas. Sendo assim, na RP, ao propormos oficinas na qual denominamos: Oficinas de Sabores estamos a pensar constantemente para fora dos muros e espaços acadêmicos, em que pudemos observar e investigar outros ambientes de ensino e aprendizado, no intuito de fomentar o pensamento crítico-analítico à ciência moderna enquanto futuro educadores e educadoras, em buscamos trilhar novos caminhos em que potencializam a prática docente, em consideração os fundamentos teóricosmetodológicos e o estilo de vida dos educandos (SANTOS et al., 2019; RIGOTTO; ROCHA, 2014 apud LEÃO, MELO; GOMES, 2015).

\section{Reflexões sobre a educação em tempos de pandemia de coronavírus}

Na concepção crítica do educador alemão Christoph Türcke (2020), ao se deparar com inúmeras teorias conspiratórias sobre a origem do Coronavírus (Covid-19), expressa que seja inconveniente dirigir ao referente como uma construção ou invenção do ser humano. Tendo em vista, que este pensamento e teorias sem fundamentos desconsidera a tremenda força arcaica da natureza que ultrapassa a alta tecnologia moderna da humanidade e do mundo altamente globalizado (TÜRCKE, 2020). No Brasil, a falta de investimentos na área da saúde, ciência, inovação e tecnologias proporcionaram resultados catastróficos durante o combate da pandemia do coronavírus (SAVIANI, 2020). Ao mesmo tempo, observamos os nossos direitos básicos sendo reduzidos pelas medidas impostas no avanço da doença, desde do direito à liberdade, do trabalho, da ação de ir e vir, e ao direito à educação (SAVIANI, 2020; SENHORAS, 2020; TÜRCKE, 2020).

Com a chegada da pandemia (SAVIANI, 2020), o agravamento das condições educacionais no país se tornaram um enorme desafio para os/as professores/as da rede básica de educação, que tiveram que reinventar seus métodos de ensino-aprendizagem devido a crise sanitária - cuja educação baseada no ensino remoto e de caráter excepcional - em que pudessem dar continuidade aos calendários escolares até o momento. Todavia, os estudantes por sua vez, são os que mais sofrem impactos negativos no campo 
educacional, que depararam-se com as barreiras impostas pela vulnerabilidade socioeconômica e pela falta equipamentos tecnológicos para acompanhamento das aulas durante a pandemia (SENHORAS, 2020; SAVIANI, 2020) - sendo assim, considera-se mais um retrato pela ausência fomentação de políticas públicas e educacionais em torno do desenvolvimento e amparo tecnológicos nas escolas brasileiras (SENA et al., 2019). Desse modo, no cenário pandêmico, para que modalidade do ensino remoto obtenha os mesmos impactos, e que funcionasse como um possível substituto do ensino presencial, Saviani lista três pontos condicionais:

a) o acesso de todos os alunos ao ambiente virtual propiciado pela aparelhagem representada por computadores, celulares e similares; b) considerando que alunos e professores devam estar confinados nas suas residências, estas deverão estar todas equipadas com acesso à internet;

c) é preciso que todos os estudantes preencham os requisitos mínimos para acompanharem, com proveito, o ensino remoto. Ou seja, é preciso que todos estejam não apenas alfabetizados em sentido estrito, mas também em sentido funcional e, mais do que isso, não sejam analfabetos digitais. (SAVIANI, 2020, p. 6)

Para Sena et al. (2019), ao trazer o tema sobre o uso de tecnologias no ambiente escolar, expressa que essas ferramentas multifuncionais "podem nos ajudar a compreender as mudanças do mundo e das relações interpessoais, bem como, o aprendizado proporcionado pela introdução dessas novas formas de fazer o ensino" (SENA et al., 2019, p. 195), isto é, a introdução das tecnologias nas escolas propicia novas metodologias didáticas, em que os professores/as e alunos/as possam usufruir de mais recursos da área da informática - datashow, projetor, imagens ilustrativas, jogos interativos, acesso a internet e etc. - e que não se limite apenas no quadro mágico e o livro didático (SENA et al., 2019).

Nessa mesma perspetiva os autores complementam: "através de uma metodologia dinâmica e menos tradicional, é possível envolver os alunos mais ativamente nas discussões e atividades desenvolvidas em sala de aula" (SENA et al., 2019, p. 196). Assim, entende-se que trabalhar com essas ferramentas tecnológicas dentro da escola possibilita um desenvolvimento iterativo e comunicacional entre educador e educando de certo modo, considera-se superficial compreender as tecnologias como inimiga da educação, tendo em vista que, as demandas e tecnologias educacionais surge na perspectiva de trazer novas formas de aprender e ensinar, e que deveria ser de acesso para todos/as dos diferentes parâmetros sociais. Em contrapartida, é de se considerar o comentário feito por Türcker (2020) sobre as tecnologias no âmbito educacional durante 
a pandemia, em que expressa possíveis incongruências formativas em torno do tema em questão.

Hoje, a grande incerteza está relacionada ao sistema de ensino. Se já tivéssemos digitalizado as escolas, agora não teríamos problemas, dizem os adeptos da tecnologia. Mas eles não reconhecem que certos processos educacionais elementares, que exigem entendimento e verbalização em conjunto na sala de aula, não acontecem no ensino remoto. Quanto menores as crianças, menos produtivo é o processo. O que acontece no monitor, a menos que pais atenciosos assumam a tarefa da verbalização, não é nada mais do que um passatempo. Por que o medo de admitir isso? (TÜRCKE, 2020, p. 5)

Nessa mesma linha de reflexão do ensino presencial e o ensino remoto, Santos, Silva e Belmonte (2021), basendo-se nos estudos de Santos (2020) em Portugal, assinalam que a educação mediada por tecnologias, resultou no "empobrecimento da comunicação, partilha de vivências, expressões, sentimentos, emoções, conhecimentos, práticas e saberes entre docente e discente" (SANTOS; SILVA; BELMONTE, 2021, p. 247). A ausências das relações interpessoais entre educador e educando acarretam na desmotivação entre as duas partes no ambiente de ensino e aprendizagem, os/as professores/as por suas vez, sentem-se desanimados por estarem em um ensino excepcional, com poucos alunos nas aulas e com as câmeras e microfones desligados, passando a sensação de estarem em uma sala conversando sozinhos (SANTOS; SILVA; BELMONTE, 2021).

Além disso, na pandemia, a ausência desses recursos tecnológicos por parte dos alunos/as e professores/as das redes de ensino traz evidências, que essas condições sinalizadas por Saviani (2020) e Senhoras (2020) não são preenchidas pela maioria da comunidade escolar. No Brasil pós-pandemia, o surgimento e a consolidação de pressões favoráveis a aplicação do Ensino a Distância a equivalência do ensino presencial nos remete as pautas neoliberais, em que as "tendências à conversão da educação em mercadoria na esteira da privatização que implica, sempre, a busca da redução dos custos visando o aumento dos lucros" (SAVIANI, 2020, p. 6) nessa concepção, deve-se compreender que a natureza da educação, baseia no presente em relação presencial entre aluno/a e professor/a. Nessa mesma linha, Apple (2013) expressa que

[...] no novo mercado educacional, 'liberdade' e 'escolha' serão apenas para os que tiverem condições e recursos. 'Diversidade' em educação será apenas uma palavra mais elegante para a condição de apartheid educacional" (APPLE, 2013, p. 98, grifo do autor) 
No cenário atual da educação brasileira, cabe (re)pensar a educação pós-pandemia em um futuro não tão distante, em virtude do discurso hegemônico das frentes políticas que se apresentam como um princípios organizadores e reorganizadores do sistema escolar. Um olhar crítico a esse respeito pode permitir (re)significar suas crises estrutural na sociedade, com ênfase na educação. Desse modo, pretende-se "propiciar a sobredeterminação de uma série de demandas dispersas, eles criam uma ilusão de unidade (precária e contingente) e compensam a sensação impossível de completude" (MACEDO, 2006, p. 1536). Muitos são os agentes que estão dispostos a debater as políticas públicas no âmbito da educação nacional. Entre essas estão empresas privadas e coligações financeiras como os grupos Roberto Marinho, Victor Civita, Ayrton Senna, Lemann, Natura, Volkswagen e outras mais - que estão a oferecer produtos e materiais educacionais vinculados às políticas da educação governamental. De modo que estes parceiros financeiros visam a centralização do currículo nacional unificado, como também,

[...] à produção de uma narrativa hegemônica sobre o que é qualidade na educação e sobre como atingi-la. O que está expulso dessa narrativa, o seu exterior constitutivo, é a noção de que a educação é um bem público e, como tal, precisa ser gerido. (MACEDO, 2006, p. 1545).

Em um futuro não tão distante, deve-se investigar as tendências dominantes em que visam as políticas do conhecimento e adoçam temas relacionados ao ensino domiciliar, sobrepondo as políticas educacionais excludentes para centenas de alunos e alunas das redes públicas de ensino, que não possuem condições e/ou recursos, nem o domínio técnico dessas tecnologias para acompanhamento de suas formações. É de se pensar: o que será da educação de amanhã? Quais serão as metas, os desafios desse amanhã? Como a escola pública será nesse novo amanhã?

\section{O contexto da experiência}

Devido ao surgimento da pandemia do Coronavírus (Covid-19), o país entrou em situação de calamidade pública em decorrência da propagação do vírus em escala global, notificado pela Organização Mundial de Saúde (OMS) e Ministério da Saúde (MS), em que nesse contexto todas as aulas presenciais, teve que ser suspensas. Com isso, reinventou-se a educação e espaço escolar, em que buscou-se de novos recursos tecnológicos, assim, surgiram as propostas de Ensino Remoto para crianças e 
adolescentes como um substituto do ensino presencial excepcionalmente nesse período da pandemia.

Por decreto da Secretaria de Educação da Bahia (SEC/BA) as aulas das redes de ensino do Estado da Bahia retornaram ao ano letivo no dia 15 de Março de $2021 \mathrm{em}$ referência às incongruências formativas dos/as seus alunos/as no ano de 2020. Contudo, é de se observar, pouco engajamento dos/as alunos/as ao ensino remoto, por razões financeiras, vulnerabilidade econômica durante a pandemia, e a falta de equipamentos para os acompanhamentos das aulas remotas (smartphones, computadores, chips, internet e etc.).

Considerando este contexto, foi proposta uma oficina de modo síncrono e assíncrono como Atividade Complementar com os estudantes do ensino médio, em que pudesse durante o ensino remoto, investigar novas desigualdades sociais e a vulnerabilidade econômica decorrente da Covid-19 aplicada aos trabalhadores das artes no Brasil. Assim, seria importante observar, como a pandemia trouxe à tona a crise dos nossos sentidos e sentimentos das relações humanas e interpessoais, em que de certa forma, as expressões e representações artísticas, puderam retratar as vivências e resistências no cenário cotidiano em referência à crise sanitária e suas diversas narrativas. Destarte, fomentar a discussão das diversas barreiras e limitações que foram pregadas a categoria artística, artesãos, trabalhadores autônomos e informais tornou-se o escopo da proposta dessa oficina, que nesse contexto é era de grande importância pensar as dificuldades dos/as artistas locais durante a pandemia.

\section{MÉTODO}

Para analisar as experiências desenvolvidas da Residência Pedagógica partiu-se de um recorte temático da proposição de uma oficina, executada na unidade escolar, sob orientação dos/as professores/as responsáveis do núcleo da Residência Pedagógica na unidade concedente. As atividades foram desenvolvidas em um colégio da rede estadual de ensino, situado na cidade de Porto Seguro/BA e fazem parte do subprojeto de área, que por sua vez, trata-se do núcleo de História, no qual foi iniciada a prática docente no Módulo I. Ademais, também existem outros núcleos que se coligam em espécie de rodízio: o núcleo de Artes em uma escola da rede municipal de ensino e o núcleo de Sociologia no Instituto Federal da Bahia (IFBA), em que ressalta o conceito de 
interdisciplinaridade entre os núcleos citados e as Licenciaturas Interdisciplinares (LIs) da UFSB.

Neste módulo, os residentes ficaram responsáveis em propor uma oficina de Atividade Complementar (AC) para os alunos de $3^{\circ}$ Ano de turno noturno, que consequentemente, partiu das discussões, leituras, revisões bibliográficas em que resultou na implementação do plano de aula para execução das oficinas, denominado: Oficina de Saberes, abordando um conceito interdisciplinar entre as áreas do conhecimento e temas diversos, como artes, história, filosofia, memórias-narrativas, ancestralidades, racismo e pandemias. As atividades das oficinas foram realizadas em encontros síncronos e assíncronos, seguindo as orientações determinadas pela direção e professores/as da instituição de ensino. Os encontros das oficinas ocorreram em dois momentos: momento assíncrono e síncrono.

\section{Descrição da Oficina}

Após a formação inicial promovida pelos professores/as e instrutores da Residência Pedagógica com temas relacionados a educação, elaboração de material didático e levantamento de referencial teórico, os residentes inseridos na instituição de ensino, iniciaram a prática docente através das oficinas. Neste contexto, foi proposta a oficina intitulada: As dificuldades dos/as artistas locais na promoção da arte durante a pandemia, devido ao eventual cenário de crise sanitária em que vivemos, discutindo as relações de mudanças e vivências, vulnerabilidade ocorridas na pandemia.

Assim como as demais oficinas, os encontros desta oficina ocorreram em dois momentos: momento assíncrono e síncrono. O primeiro momento assíncrono, se deu a partir da elaboração e gravação da oficina em um tempo curto (15 minutos), disponibilizado no Google Classroom, em que pudesse sintetizar o tema e as questões a serem abordadas no vídeo, como: o nascer da obra de arte, vivências e simbolismo na percepção do artista; exibição do curta-metragem Tempo de Pipa (2020, vídeo exclusivo autoral); abordamos também temas relacionados a Lei Aldir Blanc (BRASIL, 2020) e seus recursos emergenciais para o setor cultural durante a pandemia do coronavírus.

Para a confecção desta aula assíncrona, partiu-se da criação de um slide sobre o tema retratado na plataforma Google Apresentação, posteriormente, a gravação da videoaula ocorreu na utilização da plataforma Loom: Video Messaging for Work que possibilitou em apresentação dinâmica do conteúdo proposto. Além da plataforma ser 
gratuita, disponibiliza a gravação em ótima qualidade, e possui ferramentas de rápida edição vídeo e compartilhamento.

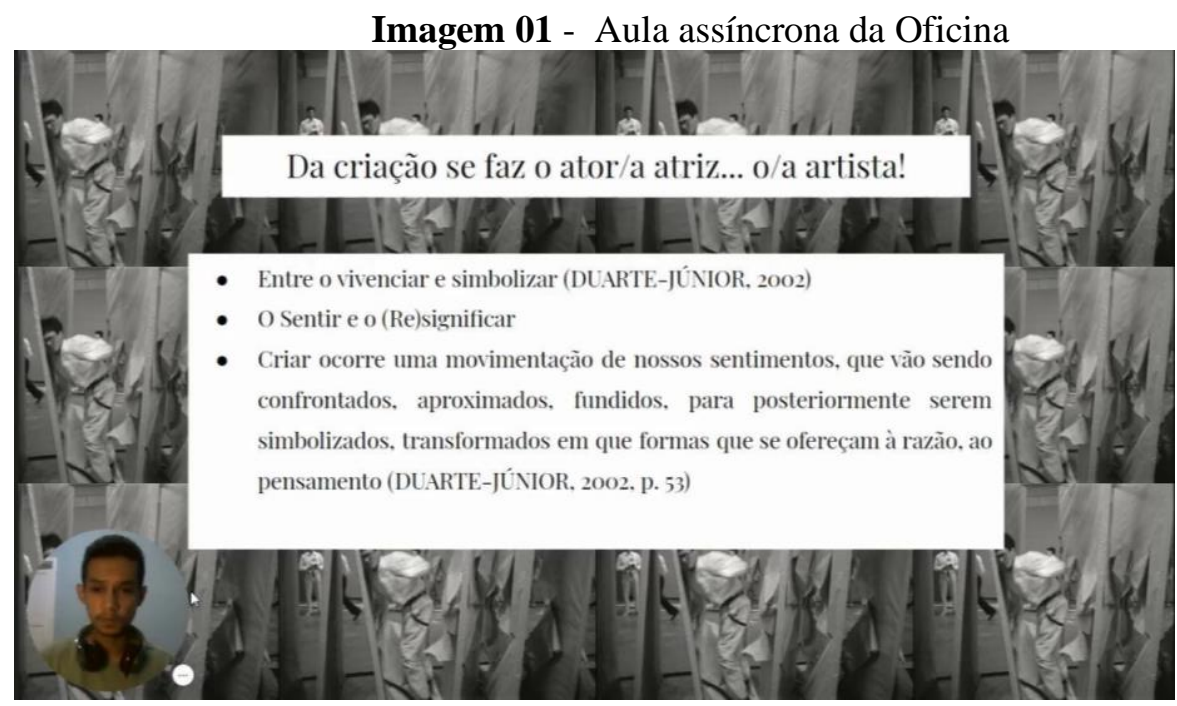

Fonte: Autoria própria

A segunda parte da oficina trata-se de um momento síncrono com os estudantes, na qual foram tiradas algumas dúvidas sobre o tema e auxiliar na produção dos textoscomentários. Através da plataforma Google Meet construímos um plano de aula na qual, junto ao professor preceptor, buscou-se trazer algumas indagações para os estudantes baseando-se em alguns exemplos das vivências dos artistas durante a pandemia.

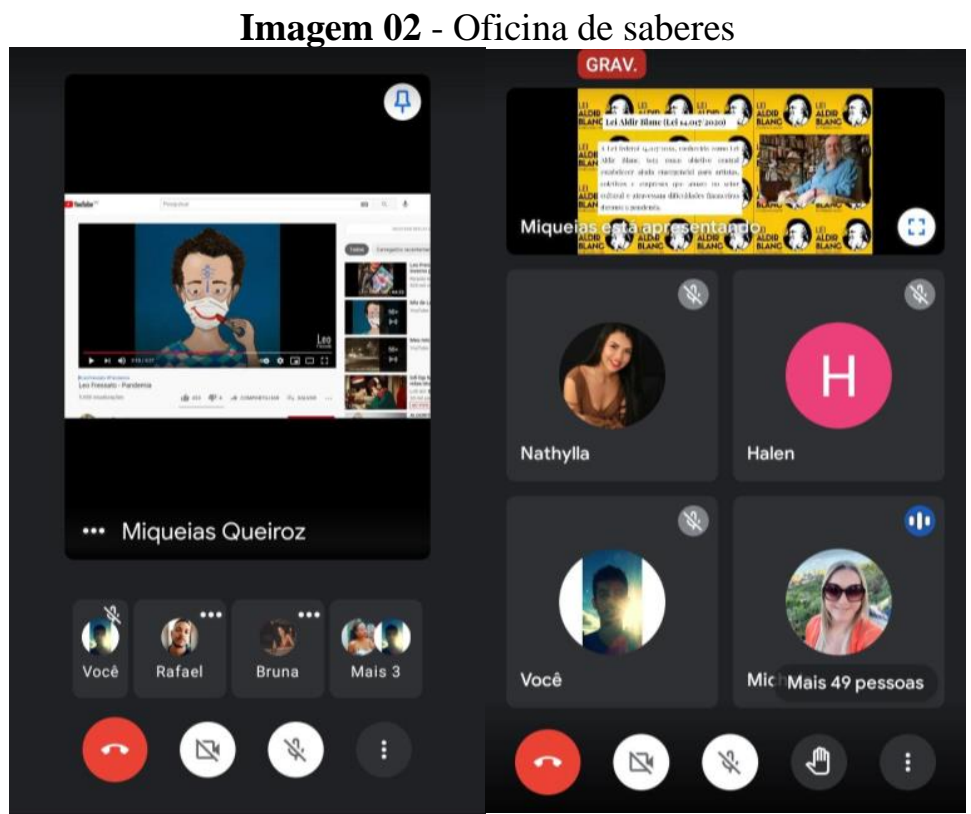

Fonte: Autoria própria 


\section{Participantes}

Participaram desta oficina estudantes do $3^{\circ}$ Ano do ensino médio de turno noturno regularmente matriculados na instituição de ensino. A oficina constou com a participação de 15 alunos/as durante a aula assíncrona, em outros momentos podendo chegar a 50 participantes no momento síncrono, uma vez que participaram outras turmas da escola. No contexto do ensino remoto, maioria desses estudantes são oriundos de zona periférica do município retratado, e possuem um perfil de vulnerabilidade socioeconômica bastante acentuado. Durante o percurso, foram inúmeros fatores que contribuíram para a não participação das oficinas. Da composição dos relatos desta pesquisa, destacamos quatro textocomentários de estudantes do sexo feminino, com idade entre 15 e 25 anos.

\section{COLETA E ANÁLISE DOS DADOS}

A análise dos dados parte-se das experiências coletadas junto aos estudantes da instituição de ensino básico. Aqui se destacam as principais ideias dos/das depoentes, evidenciando as suas percepções sobre as questões classe artística no contexto da pandemia do coronavírus. As ações da Residência Pedagógica foram realizadas em um colégio de ensino médio da rede estadual, entre os meses de Novembro do ano de 2020 e Abril de 2021. Todos os discentes da instituição foram devidamente inscritos em e-mails promovidos pela SEC/BA e posteriormente realocados em salas virtuais, dessa forma, os residentes e os professores/as das redes de ensino do estado puderam organizar seus materiais, oficinas, tarefas, exercícios, executar plano de aulas e outras ferramentas disponibilizadas pelo Google Classroom, em que pudemos orientar e compartilhar as oficinas buscando discutir os mais diversos temas.

No final, após os estudantes assistirem a oficina, foi proposto a elaboração de um texto-comentário sobre o tema, assinalando as dificuldades dos/as artistas locais ou de determinado localidade em que retratasse as mudanças cotidianas de artistas e os modos de produção dos mesmos, e suas relações com o público nas suas variáveis linguagens: música, cinema, teatro, performance, literatura, pintura, artes visuais, artesanato e etc., e que desse modo, selecionamos quatro experiências para compor este relato.

A percepção dos estudantes da Oficina de Saberes sobre o tema: As dificuldades dos/ as artistas locais na promoção da arte durante a pandemia

A oficina proposta buscou refletir sobre a importância da arte-educação enquanto potencializador de conhecimento no ensino público, ressaltando o papel fundamental 
dos/as professores/as de artes em sala de aula, destacando o conceito de arte-educação e seus fundamentos formativos para educação básica, refletindo sobre as seguintes questões:

- Qual a importância da arte-educação no espaço escolar?

- Por que falar emoções, imaginações e sentimentos é essencial para a formação humana?

- Qual é o papel da arte nas formações individuais e coletivas?

- Qual a importância do professor/a de arte no espaço escolar?

Através das orientações dadas na oficina, foram coletadas respostas às perguntas feitas acima, a partir de uma escrita livre.

Texto-comentário sobre Oficina de Saberes: As dificuldades dos/as artistas locais na promoção da arte durante a pandemia - Aluna do $3^{\circ}$ Ano C

Reinventar e adaptar suas atividades ao público, devido ao distanciamento social. Foi uma maneira que os músicos tiveram que fazer, devido ao isolamento social, um exemplo foram as lives. Vemos isso desde o artista/músico de barzinho, que luta para ser reconhecido e apresentar seu trabalho, como os grandes, então vou falar de um artista grande, que como os pequenos locais fizeram da mesma forma. Por exemplo, [o cantor] Wesley Safadão anunciou pelo Instagram, que será gravado o DVD WS Em Casa 2. A princípio, a gravação seria em um show em São Paulo, mas foi cancelado devido à pandemia do novo coronavírus, uma campanha de arrecadação de fundos para auxiliar no combate às consequências da covid-19. Nisso logo mostra a mudança que houve do contato do artista com o público nesse distanciamento social. $\mathrm{O}$ artista precisa do seu público, pois há aí uma retroalimentação. As lives surgem não só como uma maneira de manter a interação dos artistas com o público, mostrando muitas vezes que seus ídolos estão na mesma situação e é muito importante que os artistas alertem as pessoas sobre permanecer em casa, como também para que haja arrecadação de valores, revertidos em doação para as famílias mais vulneráveis. (Maria Clara)

O texto-comentário da aluna Maria Clara $^{2}$ traz uma perspectiva do cenário contemporâneo do mercado das artes em relação ao momento da pandemia do Coronavírus. Neste ponto destaca-se o papel fundamental da arte durante $\mathrm{o}$ distanciamento social, como também o desdobramento devido às circunstâncias que foram impostas aos músicos/artistas. A música é uma linguagem bem popular, o/a cantor/a possui uma capacidade interpessoal, a construir um corpo-palco que fomenta sua interação com o seu público, assim como retratada pela aluna.

O trabalhador do ramo musical sofreu duras alterações com a implementação de normas de biossegurança, como o distanciamento social, que apesar dessas barreiras impostas pela pandemia, continuaram a exercer suas atividades autônomas e/ou informais em bares e restaurantes das cidades. A entender que a exercer tal profissão artistas, músicos e bandas - não trata-se de desrespeitar as normas estabelecidas pelos órgão competentes da saúde, mas sim como uma forma de necessidade financeira dessas

2 Visando preservar o anonimato da respondente, optou-se por usar um nome fictício. 
pessoas sobreviverem neste momento excepcional. Para tanto, ações de exposição durante a crise, não descartam a possibilidade de aumento significativo do número de casos da Covid-19. Desse modo, a utilização de lives pelos profissionais do ramo musical, como expresso pela estudante, tornou-se o meio mais seguro entre a relação artista-espectador, ainda que instrumento bastante sofisticado para os profissionais mais humildes.

Denomina-se "artista grande", músicos com carreiras consolidadas, a exemplo do cantor Wesley Safadão, em que no período de isolamento social, buscou meios de comunicação que aproximaram o seu público com o novo ambiente de trabalho. Assim, além do cantor assumir o compromisso de dialogar com seus ouvintes, arrecadar fundos e conscientizar parte da população sobre o momento em que vivemos, a respeitar restrições para diminuição de contágio do vírus, é notório que artistas de grande porte possuem plataformas de monetização o que possibilita obter recursos financeiros. Entretanto, parte dos artistas/músicos menores, muitos não possuem engajamento e/ou técnica de manuseio de ferramentas e plataformas digitais, além disso, a necessidade de adquirir novos equipamentos gera custos extras, aumentando a sensação de insegurança quanto a promoção das lives. De todo modo, a discente expressa que o artista necessita da presença do seu público, que como tal, também precisa da interação do artista durante um momento excepcional da crise sanitária.

Texto-comentário sobre Oficina de Saberes: As dificuldades dos/as artistas locais na promoção da arte durante a pandemia - Aluna do $3^{\circ}$ Ano C

A chegada da pandemia trouxe muitas [mudanças], e uma delas foi no meio artístico, que tem contribuindo com a economia local. Mas alguns artistas tiveram que inovar, como a história de Bruna Luiza que trabalha no circo, ela relata que com a chegada da pandemia teve que cancelar apresentações e tendo que se mudar com sua família pro interior de Goiás em Alexânia, onde o custo de vida [é] mais barato, e assim passou a viver com o Auxílio Emergencial do Governo [Federal], enquanto seu marido fazia live para arrecadar doações para ajudar a se manter. E assim não é diferente com muitos artistas que com a pandemia teve que mudar e usar sua criatividade para continuar passando sua educação e sua cultura através da arte. (Ana Carolina)

A aluna Ana Carolina ${ }^{3}$ destaca em seu texto-comentário as eventuais mudanças cotidianas ocorridas no meio artístico e as dificuldades da promoção da arte durante a situação de calamidade pública no interior do Brasil. No caso retratado, trata-se da história da artista circense Bruna Luiza, em que meio a pandemia, às apresentações do circo tiveram que parar totalmente suas atividades durante o período de distanciamento social, até mesmo se locomover para outra cidade com seus familiares, em busca de estabilidade

3 Visando preservar o anonimato da respondente, optou-se por usar um nome fictício. 
financeira por meios de outras atividades não artísticas. A pandemia expôs a fragilidade dos/as artistas circenses não somente do modo financeiro, como também de forma humanitária, política e emocional, principalmente quando se trata de pequenas companhias de circo, que necessitam de acompanhamento e assistência básica de saúde e educação. Foram inúmeras alternativas que os/as artistas circenses recorreram para lidar com a pandemia, entre eles foi o trabalho informal, como aponta a estudante.

De modo excepcional, a venda de guloseimas nas avenidas das cidades e executar apresentações circenses em vias públicas, praças e semáforos - com seus malabares e cartolas mágicas - tornou-se um novo cenário cotidiano dessas pessoas para conseguir recursos financeiros no intuito de sustentar suas famílias. As apresentações em formato de lives, promovida por prefeituras, assistência social ou de maneira autônoma, também foi um meio do circo levantar fundos, como também recolher doações de cestas básicas, remédios, itens pessoais, e o mais importante mostrar para o seu público que o circo está vivo, independente da razão ou circunstância na qual foi empregada, é um alívio de espírito - em que o circo e a prática da arte circense cura e inspira a alma. O circo que muitas vezes é composto por famílias que passam a sua prática artística em gerações - de pai e mãe para filho e filha - destacamos como este grupo pode facilmente ocorrer uma situação de vulnerabilidade econômica e apresentar riscos à saúde, integridade física e bem-estar dessas pessoas no período pandêmico. E que dessa maneira, o Estado possui um papel fundamental de aparar essas pessoas através de recursos públicos, auxílios emergenciais e culturais que possibilite ajudar essas famílias.

Texto-comentário sobre Oficina de Saberes: As dificuldades dos/as artistas locais na promoção da arte durante a pandemia - Aluna do $3^{\circ}$ Ano C

O coronavírus está afetando diretamente a produção cultural pelo mundo. Assim como os comércios e a indústria de turismo, a pandemia fez com que milhares de espetáculos fossem interrompidos. Diante disso, a situação da classe artística se mantém delicada. Na Alemanha, após meses fechado, o Teatro de Wiesbadena, voltou a ter um concerto. No entanto, medidas como distância de no mínimo três assentos para separar os espectadores e a utilização de máscaras foram necessárias para acompanhar a apresentação. No Brasil, o plano para a saída da quarentena, divulgado recentemente pelo Estado de São Paulo, mostra teatros e cinemas na última fase de abertura (azul), desde que sejam respeitados [os] protocolos de higiene e distanciamento social. "Passaremos por um período de transição com cuidados específicos, como uso de máscaras e distanciamento entre espectadores, até que possamos retornar gradativamente ao normal", afirma Marcelo Braga, pesquisador e coordenador do Curso de Teatro da Universidade Anhembi Morumbi. Com essas medidas, artistas precisarão adaptar a forma que interagem com o público e com os parceiros de palco. "Os diretores e atores terão que, durante esse período, adaptar as marcações de cena para que essa distância se mantenha. Será uma nova forma de fazer teatro. Após esse período de restrições, acredito que, aos poucos, as atividades como peças e consertos possam ir retornando ao normal. Artistas são criativos e encontrarão formas de reinvenção das artes cênicas. (Sandra) 
Neste texto-comentário, a estudante Sandra ${ }^{4}$ comenta e cita uma matéria do Consumidor Moderno em que assinala os desafios dos profissionais das artes cênicas referente a situação da pandemia do Coronavírus. O teatro assim como as demais linguagens artísticas como a música, a dança e o cinema, estão a depender primordialmente do público e da aglomeração das pessoas para sobreviver. Estamos falando de espaços culturais, composto por atrizes, atores, dançarinos/as e performers que depende desse ambiente de trabalho, como também, pessoas do corpo técnico diretores/as, roteiristas, figurinistas, iluminadores, maquiadores/as cinegrafistas, sonoplastas e etc. - que exerce a profissão-artista e fomentador de ações culturais de pequenas e grandes cidades do Brasil. Com a chegada da pandemia, acarretou em uma série de incertezas uma vez que apresentações de peças e consertos deveriam ser paralisadas de forma imediata. Após os protocolos de biossegurança, surgia uma nova forma de fazer teatro, como no caso dos estudantes do Curso de Teatro da Universidade da Anhembi Morumbi, em que teve a necessidade de se reinventar o corpo-cênico, com seus métodos e processos de produção próprias, de acordo com as medidas sanitárias no objetivo manter as atividades e trabalhos em desenvolvimento na instituição, e principalmente apresenta-se para o público.

Seguindo a linha do comentário, podemos observar que no campo das artes, o teatro é uma fonte de inovação e experimentação em que o artista possui a capacidade de rápida adaptação, a compreender as circunstâncias impostas pela pandemia, e da importância de ter o teatro enquanto espaço cultural aberto a entreter seus espectadores. De todo modo, é de salientar a precariedade que estas instituições podem estar situadas, uma vez que grupos cênicos trabalham sem remuneração e/ou de forma voluntária. A dependência e a concentração de recursos mediantes a editais de fomento ao setor cultural - por organizações públicas ou empresas privadas - visam mais nos resultados das produções, em que por outro lado, está a corroborar a formação de estudantes-artistas.

Texto-comentário sobre Oficina de Saberes: As dificuldades dos/as artistas locais na promoção da arte durante a pandemia - Aluna do $3^{\circ}$ Ano C

\footnotetext{
Vou falar sobre as [dificuldades] que o [cantor] Belo teve na pandemia. Na entrevista, Belo conta que o lado da pandemia afetou o seu lado financeiro, e que ele fazia uma média de quinze a dezoito shows em um mês, e em um ano fez quatro e por conta da pandemia deve economizar bastante [pois] estava sem trabalho e a sorte dele é que a esposa [é] economista também. (Glória)
}

4 Visando preservar o anonimato da respondente, optou-se por usar um nome fictício. 
Apesar da aluna Glória ${ }^{5}$ não explanar tão bem seu texto-comentário, traz uma reflexão bastante interessante sobre o tema, pois retrata bem as diferenças entre as classes artísticas em um poder monetário. Isto é, artistas ou grupos renomados - como citado anteriormente pela estudante Maria Clara - sofreram menos impactos com relação a pandemia, uma vez que, estes possuem fundos e reservas em que podem bem ajudá-los durante a crise, enquanto que artistas pobres, altamente dependente do trabalho com a arte, como o caso da artista circense Bruna Luiza sofrer o duro impacto por não exercer seu trabalho resultando em uma grande vulnerabilidade econômica, sendo estes maioria desses artistas responsáveis em mover a economia e o turismo local de média e pequenas cidades. Uma vez que apresentações artísticas foram temporariamente suspensas através do Ministério da Saúde e secretarias estaduais e municipais para frear o avanço da doença, era de se pensar de onde viria o sustento dessas pessoas que não poderiam exercer suas profissões em respeito às normas sanitárias.

Ademais, a pandemia expôs a grande fragilidade e precariedade que a comunidade artística está submetida no Brasil, isto ocorre antes mesmo da grave crise epidemiológica. A começar pela questão política em constituir uma lei emergencial prevista para o setor da cultural, em que seria de suma importância para amenizar os impactos na comunidade artística, curadores e produtor cultural. Mais tarde com a protocolização da Lei de $\mathrm{N}^{\circ}$ 14.017/2020, também conhecida como Lei Aldir Blanc (BRASIL, 2020), é considerada uma vitória para o setor cultural, em que dedica-se à implementação de fundo emergencial e garantia de renda para artistas mais necessitados. De todo modo, a lei abre-se à comunidade artística, no comprometimento de fazer políticas públicas, trabalho e renda.

O segundo momento baseou-se através das aulas síncronas em que podemos discutir e tirar dúvidas sobre os temas relacionados à oficina, além disso, também era um momento em que poderíamos nos encontrar mesmo virtualmente e de tal modo, dar uma atenção especial às opiniões dos estudantes em tempo real. Primeiramente, apresentamos para os alunos/as uma série de grafite, de artistas de ruas que expressaram sobre muros e concretos das cidades do mundo inteiro, os impactos econômicos, científicos, políticos e sociais ocasionados pela pandemia de coronavírus. Entre os grafites, o que mais chamaram atenção dos estudantes foi o grafite denominado como: Love in the time of corona (2020) em que retrata um beijo de máscaras entre o presidente da China Xi Jinping

5 Visando preservar o anonimato da respondente, optou-se por usar um nome fictício 
e Donald Trump ex-presidente dos EUA, no que se refere a troca farpas políticas durante a pandemia na visão do artista de rua Eme Freethinker.

Neste contexto, os discentes assimilaram a obra da aproximação das pessoas durante a pandemia, em que segundo elas, as pessoas estariam mais caridosas e unidas em combater o vírus, e que desse modo, exemplificaram partindo das tensões políticas e militares entre EUA e Irã, em que no início de 2020 ambos países estavam exaltados, e com a chegada da pandemia, todo cenário mudou drasticamente focando em erradicar o coronavírus. Outras obras que mereceram destaque pelos estudantes foi a obra de Micha em que faz uma releitura do quadro da Monalisa de Leonardo da Vinci, e que neste caso trata-se de uma obra em preto e branco e uma Monalisa de máscara. Também, Banksy conhecido por trazer seus grafites com temas pautados em questões políticas e sociais, dessa vez trouxe uma obra de uma criança segurando uma boneca na forma de enfermeira com capa de super heroína, e que expressa uma singela homenagem ao corpo médico que atua a frente ao combate do coronavírus.

Posteriormente, apresentei para os estudantes a música Pandemia (2020) do cantor Leo Fressato (Imagem 02), uma canção que fala de amor e solidão na perspectiva na pandemia, em que o artista ressalta que a pandemia só reafirmou o distanciamento entre os amores não correspondidos, assim conforme o trecho abaixo:

Acho que agora, amor, você me entende. Pois agora meu amor. Você está igual a mim. Tá trancado na tua casa. E não beija mais ninguém. $E$ de tanta ansiedade. Tá comendo até a parede. (Pandemia, Leo Fressato)

Os estudantes ficaram intrigados com a música, assimilando com o grafite, ao ponto de se questionarem: a pandemia trouxe união ou desunião entre as relações interpessoais? O que se espera das relações humanas no mundo pós-pandemia? Uma aluna comenta que a pandemia aproximou ainda mais as famílias por passar mais tempo em casa devido ao distanciamento, de antemão, outra aluna comenta que trouxe também conflitos familiares no que se diz acerca da taxa crescente de feminicídio e de divórcios pelo mundo. A discussão durou até o final da oficina no qual se encerrou falando um pouco das vivências durante o ensino remoto. De modo, é de se observar a potencialidade que obtivemos nessa oficina, em que tratamos a vida cotidiana dos artistas e do modo de promover e fazer arte, e como está arte possui a capacidade de nos remeter a reflexões diversas em torno da nossa sociedades em que situamos. Os discentes expressaram grande satisfação pela oficina, após agradecimentos e considerações finais nos despedimos. 


\section{CONCLUINDO: "ARTE PRA QUÊ?"}

Baseando na literatura consultada, é de se pensar que ensino de artes não seja meramente compreendida como apenas uma matéria curricular nos parâmetros educacionais, sem sua devida importância comparada com as outras áreas do conhecimento, mas sim como um ensino formador para o desenvolvimento humano, no que se refere a educação estética, das emoções e dos sentimentos dos seus alunos e alunas (DUARTE-JÙNIOR, 1981; 2002). E que desse modo, “a nossa cultura tornou-se pósmoderna, regida e fragmentada pelo sistema imposto pelo capital, em que encontramos características que permeiam e se refletem na educação e nas Arte atuais" (GOMES; NOGUEIRA, 2008, p. 10), uma vez que, o ensino era ministrado aos interesses das elites no século XX por um Estado nacionalista e centralizador (GOMES; NOGUEIRA, 2008), a educação integra-se a globalização econômica e o mundo pós-modernidade. Entre avanços e retrocessos das políticas educacionais implementadas por arte-educadores, o ensino de artes se insere no espaço escolar em uma espécie de puxadinho, em que o ensino de arte por muitas vezes é equiparado apenas a uma atividade lúdica sem compromissos para a formação social e cidadã.

A presente pesquisa buscou retratar as experiências dos estudantes do ensino básico partindo da promoção e análise das oficinas com o corpo discente, em que enfatizamos a importância da arte, do/a artista e do/a arte-educador/a durante a pandemia do coronavírus em discussão dentro do espaço escolar. Notamos que parte dos/as alunos/as através das oficinas ministradas, demonstraram-se engajadas durante boa parte da trajetória da Residência Pedagógica, e compreenderam através das aulas e também por meio das suas próprias vivências as circunstâncias que são impostas a pequenos grupos em uma eventual situação de calamidade pública.

É de se destacar, que as ações desenvolvidas na Residência Pedagógica trouxeram a experiência da prática docente no espaço escolar, cuja formação possibilita um leque de conhecimentos e saberes de ensino-aprendizagem, observando o corpo discente, atuação docente, gestão escolar, como também as metodologias e incongruências formativas do alunado e de professores/as na rede básica de ensino. As experiências aqui expostas reforçam a importância do ensino de artes e do papel fundamental de arte-educadores/as, que na ocasião da oficina, mediou os debates sobre temas relevantes e cotidianos através da arte. 


\section{REFERÊNCIAS}

APPLE, M. W. A política do conhecimento oficial: faz sentido a idéia de um currículo nacional? In: MOREIRA, Antonio Flavio; TADEU, Tomaz (org.). Currículo, cultura e sociedade. São Paulo: Cortez, 2013.

BRASIL. Lei $\mathbf{N}^{\circ}$ 14.017, de 29 de Junho de 2020. Dispõe sobre ações emergenciais destinadas ao setor cultural a serem adotadas durante o estado de calamidade pública reconhecido pelo Decreto Legislativo n. 6, de 20 de março de 2020. Diário oficial da União: seção 1, Brasília, DF, n. 123, p. 1, 30 jun. 2020. Disponível em: https://www.in.gov.br/en/web/dou/-/lei-n-14.017-de-29-de-junho-de-2020-264166628. Acesso em: 20 de Out. 2021.

CATELLI, R. E. Coleção de Imagens: O cinema documentário na perspectiva da Escola Nova, entre os anos de 1920 e 1930. Campinas/SP, Educ. Soc., v. 31, n. 111, p. $605-$ 624, Abr/Jun. 2010.

DUARTE-JÚNIOR, J. F. Fundamentos estéticos da educação. São Paulo: Cortez, 1981.

Por que arte-educação?. Campinas: Papirus, 2002.

FREIRE, P. A Importância do Ato de Ler. In: A Importância do Ato de Ler: em três artigos que se completam. São Paulo/SP: Cortez, 1989.

GOMES, Karina; NOGUEIRA, Sonia. Ensino da Arte na escola pública e aspectos da política educacional: contexto e perspectivas. Rio de Janeiro: Ensaio: aval. pol. públ. Educ., 2008.

FAZENDA, I. C. A. Interdisciplinaridade e transdisciplinaridade na formação de professores. Cascavel/PR, Revista do Centro de Educação e Letras, v. 10, n. 1, p. 93$103,2008$.

FAZENDA, I. C. A.; SOUZA, F. C. Diálogos interdisciplinares em saúde e educação: a arte do cuidar. Porto Alegre/RS, Revista Educação \& Realidade, v. 37, n. 1, p. 107124, Jan./Abr. 2012.

LEÃO, F. A. F.; MELO, R. D.; GOMES, J. F. Pedagogia do território e juventudes do campo no Ceará. In: II Encontro Nacional de Pesquisas e Práticas em Educação (II ENAPPE), 2016, Natal/RN. Anais do II ENAPPE, 2016.

MACEDO, E. Base Nacional Curricular Comum: Novas formas de sociabilidade produzindo sentidos para educação. São Paulo/SP, Revista e-Curriculum, v. 12, n. 03 p.1530 - 1555 out./dez. 2014

SANTOS, E. J; ROCHA, D. C. S; CONCEIÇÃO, V. M; RIBEIRO, T. V. V. Prática da Docência: difundindo a aprendizagem no processo formativo da residência pedagógica. Salvador/BA, Revista Internacional de Análise Cognitiva - RIANCO, v. 1, n. 1, p. 19, Dez. 2019. 
SANTOS, G. M. R. F.; SILVA, M. E.; BELMONTE, B. R. COVID-19: ensino remoto emergencial e saúde mental de docentes universitários. Recife/PE, Rev. Bras. Saúde Matern. Infant., n. 21 (Supl. 1), p. 245-251, Fev. 2021.

SAVIANI, D. Crise estrutural, conjuntura nacional, coronavírus e educação - o desmonte da educação nacional. Santarém/PA, Revista Exitus, v. 10, p. 01-25, 2020

SENA, A. K. S.; COSTA, J. B. A.; FRANÇA, R.; MIRANDA, L. R. Educação nos moldes da tecnologia. Recife/PE, International Journal Education And Teaching PDVL, v. 2, n.1, p. 193-207, Jan./Abr. 2019.

SENHORAS, E. M. Coronavírus e educação: análise dos impactos assimétricos. Boa Vista/RR, Boletim de Conjuntura (Boca), v. 2, n. 5, p. 128-136, Mai. 2020.

TÜRCKEL, C. Medo e Razão em Tempos de Coronavírus. Porto Alegre/RS, Educação \& Realidade, v. 45, n. 4, p. 1-7, 2020. 